\title{
Anxiety Disorders in Pregnant Women: Causes and How to Overcome Them
}

\author{
Due Van Que ${ }^{1}$, Dung $\mathrm{Hau}^{1}$ \\ ${ }^{1}$ Public Health, Hanoi University, Vietnam \\ Received: January 20, $2021 \quad$ Received in Revised: February 22, $2021 \quad$ Accepted: March 5, 2021
}

\begin{abstract}
The article explains the origins of anxiety disorders during pregnancy, and their treatment. Pregnant women's anxiety is normally manifests itself as emotions, perceptions, and behaviors, which is mediated by biological, social, and genetic influences. Probability analysis is done of this kind. Using a survey of 1500 rural residents as a random number between 100 and 1600 produces a $200 \%$ response rate. those findings revealed that $60 \%$ of the participants had adequate reproductive age and $51 \%$ had mild to moderate anxiety, and $78.4 \%$ had high anxiety. The reasons leading to pregnant women's anxiety include their age, working status, lack of care from a boyfriend, having had previously given birth, and their wellbeing before becoming pregnant, all of the woman's family members, and maternal well-being. To resolve this is by sufficient relaxation, anti-depressants, a safe diet, and physical exercise, along with learning how to behave more positively, and by means of ourselves, or through prantal massage.
\end{abstract}

Key words: Anxiety Disorders, Biological Factors, Psychological

\section{Introduction}

Fetus anxiety is created when a person or group's sense of security is threatened due to the mother's discomfavor or resentment of change. Anxiety is a feature of both biological, psychological, and physiological origin. The symptoms shown differ between individuals. in pregnant women, this happens due to hormonal changes which allow the fetus to grow and develop until delivery. There is no way to predict the amount of fear that a pregnant woman would experience, except to look at how the mother plans for it. Many people don't recognize that being pregnant and coping with depression are interrelated and can affect each other's outlook.

If you have an anxiety disorder during pregnancy, it must be taken seriously. This is worse for his welfare. It has a considerable effect on pregnant women and their unborn babies. The infant that is developing in the womb is still suffers negative consequences from the environment. Anxieties can be damaging to both the mother and the unborn child. When under extreme tension, of course the mother would worry and get nervous. Furthermore, it also effects the fetus. Anxiety and fear during pregnancy will adversely affect both the mother and the baby There is a rise in stress as the time of birth approaches, such as during the third trimester of pregnancy.

A woman about to enter her third trimester will experience a change in her hormone levels, which causes preeclampsiaemia, and an increase in clotting factors (Sandman et al., 2006; Poudevigne \& O'Connor, 2006; Kirschbaum et al., 2009). being pregnant when in the fetal and postnatal stages, from premature to postnatal, giving birth results in a premature or full-term delivery the state of a woman during pregnancy (and long-term)pregnancy changes drastically. 
The manager is critical for those employees with lower parturitioned postpartum depression, believing it to be low self-esteem and insufficient social support. Kecemasan para persalin yangkinya rasa cemasinya teringkatut rasanya mencembabur bila orang satu dia sekirupedik-edik. 15 Mothers' milk cannot match the calories found in the rest of the milk, but milk from a mother does (emphasis on milk from a mother's mammary glands gives more nutritional value). It is frustrating when you don't know the person who is jealous of you stress reduces blood flow to the arm, causing "cold hands" If things continue to be this stressful, and you suffer continuous setbacks, your emotions will also to be worn down.

Some of the parents or their parents-in-in-law, particularly the elderly ones, spend several sleepless nights worrying. Sick or pregnant women may provide a negative effects to their unborn children. Problems with premature delivery are worse with low birth weights, in which there is danger of cephalia, and preterm delivery in which emotional stress has a higher priority, delivered babies are likely to have low weights.

\section{Methods}

This type of research is quantitative research. The entire data collected is then verified and completed according to the actual situation. The basis for decision making is based on probability. 200 people as a sample from 1550 people in 4 rural areas.

\section{Factors Influencing Pregnant Women's Anxiety Disorders}

Risk factors that cause anxiety in pregnant women are maternal characteristics including education, age, employment status, reproductive factors including unwanted pregnancy/unplanned pregnancy, previous pregnancy and childbirth experience, maternal health status, maternal relationship with spouse, and family support.

Family support is the best preventative intervention strategy in helping family members with anxiety-affected problems aimed at improving adequate family support.

\section{Age-based anxiety levels}

Maternal age is one of the factors of anxiety level in pregnant women. Pregnancy of mothers with a risky age can be a cause of maternal anxiety. Pregnant women with a risky age can occur disorders in the fetus or abnormalities that can cause anxiety to pregnant women, especially primigravida.

Pregnant women with age are not at risk of experiencing higher levels of anxiety, this condition can be caused by one of the factors of pregnancy parity where in theory it is mentioned that the parity factor is one of the causes of maternal anxiety in the face of childbirth where the majority primigravida experience severe anxiety because it has no previous experience of childbirth.

Table 1. Based on Age and education of pregnant women

\begin{tabular}{|l|c|c|}
\hline Age and education of pregnant women & Amount (n) & Percent (\%) \\
\hline Mating age of pregnant women & & \\
\hline Child age (12-18 years old) & 80 & 40 \\
\hline Healthy reproductive age (19-49 years) & 120 & 60 \\
\hline Pregnant women's education & & \\
\hline
\end{tabular}




\begin{tabular}{|l|c|c|}
\hline Enough (High School) & 102 & 51 \\
\hline Low (Not finished until Junior School) & 98 & 49 \\
\hline
\end{tabular}

\section{Anxiety levels based on gestational age}

Based on the characteristics of gestational age, mothers with Trimester 1 mostly experience mild anxiety. I had moderate anxiety and there was no mother with severe anxiety and panic.

Mothers with Trimester 2 sometimes experience mild anxiety experiencing moderate anxiety and there are no mothers with severe anxiety and panic (Brockington et al., 2006; Macbeth \& Luine, 2010; Lebowitz et al., 2015). Most of the respondents experienced mild anxiety, that the mother with a 2 nd trimester pregnancy the anxiety she felt began to decrease. In the 2nd trimester the mother's anxiety about her pregnancy began to decrease because pregnant women began to be able to protect and provide for the fetus, besides the mother also began to be interested to know the situation.

The 3rd trimester of pregnancy is a period of vigilance, at this time the mother is anxious about the life of the baby who will be born whether the baby will be born normally or abnormally. In addition, the mother will also imagine how the pain will be felt during childbirth. Anxiety of pregnant women will increase when gestational age enters the 3rd trimester. Increased maternal anxiety in the 3rd trimester is associated with the proximity of pregnant women to the birth of the baby.

Table 2. Data Distribution of Anxiety Levels Based on The Age of Pregnant Women

\begin{tabular}{|c|c|c|c|c|c|c|c|c|c|c|}
\hline \multirow{2}{*}{$\begin{array}{l}\text { Gestational age of } \\
\text { pregnant women }\end{array}$} & \multicolumn{2}{|c|}{ No anxiety } & \multicolumn{2}{|c|}{$\begin{array}{c}\text { Mild } \\
\text { anxiety }\end{array}$} & \multicolumn{2}{|c|}{$\begin{array}{l}\text { Moderate } \\
\text { anxiety }\end{array}$} & \multicolumn{2}{|c|}{$\begin{array}{l}\text { Severe } \\
\text { anxiety }\end{array}$} & \multicolumn{2}{|c|}{ Total } \\
\hline & $\mathrm{n}$ & $\%$ & $\mathrm{n}$ & $\%$ & $\mathrm{~N}$ & $\%$ & $\mathrm{~N}$ & $\%$ & $\mathrm{~N}$ & $\%$ \\
\hline Young age & 0 & 0 & 0 & 0 & 1 & 4,4 & 4 & 12,5 & 5 & 15,62 \\
\hline Age enough & 8 & 23,3 & 10 & 28,7 & 8 & 23,3 & 0 & 0 & 26 & 81,25 \\
\hline Old age & 1 & 2,7 & 0 & 0 & 0 & 0 & 0 & 0 & 1 & 3,12 \\
\hline Total & 9 & 26 & 10 & 28,7 & 9 & 27,7 & 4 & 12,5 & 32 & 100 \\
\hline
\end{tabular}

\section{Causes of Anxiety Disorders in Pregnant Women}

Mothers who do not participate in physical activity have a greater level of fear than mothers who work outside the house (Anderson et al., 2003; Carver et al., 2010; Nelson \& Nelson, 2010). Mothers who participate in physical sports develop more awareness about their pregnancy, making them feel calmer than mothers who do not, according to a survey. Work is said to be influential in stressors, but anyone who participates in events outside the home gains a lot of control from peers and diverse facts and interactions.

Any mothers who have struggled with trauma or other mental health issues have varying reactions to pregnancy. Every individual is different, everybody is different, and each pregnancy a woman has would have its own set of consequences and symptoms.

It is not uncommon to be pregnant and nervous at the same moment. For many new moms, early pregnancy is thrilling, but it is often frightening for those who have suffered previous miscarriages 
or who might have genetic or physical health issues that place them at risk of losing a baby too soon.

Anxiety disorders are caused by the risk of miscarriage, and normally appear in the early stages of pregnancy. The likelihood of miscarriage is greatest during the first trimester. This is often a time of worry among mothers who may not want to become pregnant, when they worry if their acts when pregnant may harm the fetus unintentionally.

The first few weeks of an unintended pregnancy may be exhausting since newly pregnant mothers must consider their potential arrangements for finances, relationships, and other places that would be changed by the baby's arrival. Mothers will still be concerned with how their jobs would be impacted, as well as the possibility of taking maternity leave after the baby is born.

These concerns may be the trigger of anxiety disorders when pregnant, particularly in single mothers or women in low-income circumstances, and they are a source of considerable concern, causing tremendous stress on the mother and her son.

The possibility of miscarriage is significantly reduced after a woman completes the second and third trimesters of pregnancy, and she expects to have a fetus deserving of life. Genetic and blood checks are used to rule out any anomalies or fetal health problems that need to be monitored right before or after the baby is born. This good news relieves the mother's and family's great relief after the evaluation is completed and there are no symptoms of complications.

As the examination reveals complications again, this is frequently the source of psychological issues in older women who are pregnant. Fears about an adverse pregnancy (depending on the diagnosis) and worries about caring for the infant and providing them with the best possible quality of life after birth are major causes of anxiety.

No matter how badly they want to, not all parents have the resources to care for children with serious deformities or permanent health problems, and this will trigger lifelong concerns and impact several other facets of the family's future.

\section{How to Overcome Anxiety Disorders in Pregnant Women}

Several levels of self-supply may be used in overcoming the triggers of anxiety disorders when pregnant at a young age. Most maternity referral centers are eager to assist mothers in receiving the treatment and help they need. Which may take the form of physical support, such as delivering blood checks and ultrasounds to people lacking benefits, or documents to potential parents to aid them in being federal assistance beneficiaries.

Food education, in addition to medical treatment, is very helpful in supplying the correct nutrition for mothers when they are pregnant, as well as powdered milk and baby solid food after the infant is born. Many also provide parenting courses for babies and young children and educate about embryonic growth, breastfeeding, and parenting. For pregnant women who are experiencing anxiety problems, below are few tips about how to resolve the triggers.

Pregnant women need to get adequate sleep every day because lack of sleep will induce depression and anxiety in the mother. A good night's sleep will help the baby get the nutrition it needs, in addition to resting the body.

If you get exhausted during your workouts, take a break and rest your pregnant body. Pregnant women should sing a song for the baby or encourage him to talk whilst they are sleeping. This 
practice is beneficial for maintaining closeness between pregnant women and their fetuses in addition to being entertaining.

Anti-Depressant Drugs; A quick option for many mothers who experience depression and anxiety during pregnancy is antidepressant medication. There have been several medications available and used over the years with the lowest risk of side effects or defects. This is a great option for mothers who need something quick and effective; although with all treatments, there is always the possibility of not helping because the body's chemistry is changing, and other forms of treatment need to be used.

Adopt a healthy and balanced diet; Another way pregnant woman can do to overcome anxiety during pregnancy is to meet the nutritional needs every day. Eating nutritious food is not only good for maintaining the health and development of the fetus, but also the physical and psychic health of pregnant women. During pregnancy, consume foods rich in vitamins, minerals, omega-3 fatty acids. Do not forget, drink at least 1.5 liters of water per day to avoid dehydration while pregnant.

Meditation and Positive Thinking; Some of the non-treatment mechanisms of the cause of anxiety disorders while pregnant are meditation. This will help the mother naturally to relax, calm her mind and body, and handle stress better. With mental anxiety coupled with physical discomfort, meditation is the ideal choice for pregnant women. It doesn't hurt to read a book or look for a variety of information about pregnancy, but keep thinking positively and not easily believe in information whose source is unclear. Try not to dig up information about the creepy things that can happen in pregnancy. Stay focused on the present, what is going on, and how pregnant woman feels in living it.

Prenatal Massage; Finding a professional who provides prenatal massage is one of the best ideas to overcome the causes of anxiety disorders while pregnant. A pregnant woman can't carelessly get this type of massage because of pressure points on the body that can accidentally trigger childbirth too early.

A person who specializes in prenatal massage knows exactly where to relieve tension safely and provide significant pain relief and relaxation for the future mother. It is a beneficial and very healthy stress reliever for mothers and babies by reducing pain, encouraging good circulation throughout the body, and relieving anxiety

Sports; Exercise, if necessary, is often a safe way to calm and brace the body for the birthing period. While not all mothers are mentally capable of vigorous exercise, a thirty-minute stroll many days a week will significantly enhance physical and mental symptoms. Heavy lifting can always be avoided when pregnant. Do a gentle cardio that is suitable for pregnant mothers.

Mental Health Professionals; Getting support from a certified mental health provider is indeed a good way to cope. Through enlisting the help of a specialist. This will aid in the coping and healing process for pregnant mothers. Often, have a positive partnership with pregnant women and provide a clear understanding of their needs. One of the easiest ways to recognise and reduce the signs and triggers of anxiety disorders when pregnant is to seek clinical support.

\section{Conclusion}

Anxiety and anxiety in pregnant women if not handled seriously will have an impact and influence on the physical and psychic both the mother and the fetus. Increased Anxiety in pregnant women will be when the delivery schedule is closer that is entering the third trimester, the mother begins 
to think about the process of childbirth and the condition of the baby to be born. Anxiety of pregnant women arises due to fear and one of the most experienced fears experienced by pregnant women is anxiety and fear in the face of childbirth and will have a negative impact when not handled. In this case the support of the family is very concerned in overcoming anxiety and worries in pregnant women. Along with a supportive environment is also needed in overcoming anxiety in pregnant women so that pregnant women can give birth safely and give birth to children in a healthy and healthy state.

\section{References}

Anderson, P. M., Butcher, K. F., \& Levine, P. B. (2003). Maternal employment and overweight children. Journal of health economics, 22(3), 477-504.

Brockington, I. F., Macdonald, E., \& Wainscott, G. (2006). Anxiety, obsessions and morbid preoccupations in pregnancy and the puerperium. Archives of women's mental health, 9(5), 253-263.

Carver, A., Timperio, A., Hesketh, K., \& Crawford, D. (2010). Are children and adolescents less active if parents restrict their physical activity and active transport due to perceived risk?. Social science \& medicine, 70(11), 1799-1805.

Kirschbaum, C., Tietze, A., Skoluda, N., \& Dettenborn, L. (2009). Hair as a retrospective calendar of cortisol production-increased cortisol incorporation into hair in the third trimester of pregnancy. Psychoneuroendocrinology, 34(1), 32-37.

Lebowitz, E. R., Scharfstein, L., \& Jones, J. (2015). Child-report of family accommodation in pediatric anxiety disorders: Comparison and integration with mother-report. Child Psychiatry \& Human Development, 46(4), 501-511.

Macbeth, A. H., \& Luine, V. N. (2010). Changes in anxiety and cognition due to reproductive experience: a review of data from rodent and human mothers. Neuroscience \& Biobehavioral Reviews, 34(3), 452-467.

Nelson, M. K., \& Nelson, M. K. (2010). Parenting out of control: Anxious parents in uncertain times. NYU Press.

Poudevigne, M. S., \& O'Connor, P. J. (2006). A review of physical activity patterns in pregnant women and their relationship to psychological health. Sports medicine, 36(1), 19-38.

Sandman, C. A., Glynn, L., Schetter, C. D., Wadhwa, P., Garite, T., Chicz-DeMet, A., \& Hobel, C. (2006). Elevated maternal cortisol early in pregnancy predicts third trimester levels of placental corticotropin releasing hormone $(\mathrm{CRH})$ : priming the placental clock. peptides, 27(6), 1457-1463. 